\title{
Palifosfamide Tromethamine
}

\author{
National Cancer Institute
}

\section{Source}

National Cancer Institute. Palifosfamide Tromethamine. NCI Thesaurus. Code $C 95703$.

A synthetic mustard compound of the tromethamine (tris) salt of palifosfamide (Isophosphamide mustard), with potential antineoplastic activity. As the stabilized active metabolite of ifosfamide, palifosfamide irreversibly alkylates and crosslinks DNA through GC base pairs, resulting in irreparable 7-atom interstrand crosslinks. This leads to an inhibition of DNA replication and ultimately cell death. Unlike ifosfamide, this agent is not metabolized to acrolein or chloroacetaldehyde, metabolites associated with bladder and CNS toxicities. In addition, because palifosfamide does not require activation by aldehyde dehydrogenase, it may overcome the tumor resistance seen with ifosfamide.

Stabilization with tris instead of lysine further increases stability and may further decrease nephrotoxicity. 